\title{
Representing a conceptual model for integrating Project Management Information Systems in project-based organizations
}

\author{
Saeed Ghorbani $^{1^{*}}$, Aboutaleb Shafaghat ${ }^{2}$ \\ Malek Ashtar University of Technology, $\operatorname{Iran}^{1,2}$ \\ sgh14@yahoo.com ${ }^{l^{*}}$,shafaghat@mut.ac.ir ${ }^{2}$
}

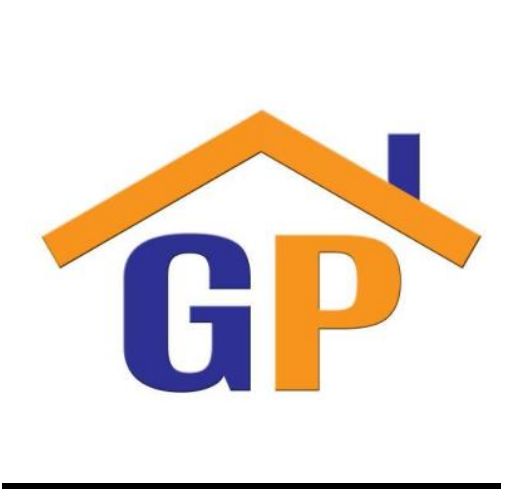

Article History

Received on 31 January 2021

$1^{\text {st }}$ Revision on 2 February 2021

$2^{\text {nd }}$ Revision on 20 February 2021

Accepted on 23 February 2021

\begin{abstract}
Purpose: This paper aimed to introduce a comprehensive model for integrating project management information systems in projectbased organizations.
\end{abstract}

Research methodology: The proposed model is presented hierarchically through a comprehensive literature review and a review of several national projects in Iran. Validation of this model was done in two ways. On the one hand, expert opinions were asked about it through several interviews. On the other hand, the model was used in some national projects and its deficiencies were identified. Finally, the necessary modifications were made to the model.

Results: In this study, it became clear that a comprehensive, integrated project management information system at its macro level should consist of three subsystems, including project warden, project administrator and project employer that mutual exchange of information should be done well between them. It was also found that this mutual information exchange should also exist among the components of each of these subsystems.

Limitation: This research only described in project based organizations.

Contribution: The Project Management Information System (PMIS) model provided in this research is the most comprehensive models in this scope for project-based organizations that have considered all aspects of project management.

Keywords: Project management, PMIS, Project-based organizations, Integrated model

How to cite: Ghorbani, S., \& Shafaghat, A. (2021). Representing a conceptual model for integrating Project Management Information Systems in project-based organizations. Annals of Management and Organization Research, 1(3), 235-249.

\section{Introduction}

To understand the information of a project, we need to look beyond this concept. Many effective parameters affect the information environment (Genc, Dayan, \& Genc, 2019). For a project to succeed in information management, a detailed analysis of how to properly deal with information elements is necessary. There are many elements, dimensions, levels and related people that interact with the environmental information entering the management information systems and affect it (Choo, 2002; Serrador \& Pinto, 2015). Project information is collected and used around the "need to know" axis. The purpose of collecting and accessing information is to meet the information needs of sponsors, managers, partners and other project owners in order to make the best decisions possible (Zahedi \& Khanachah, 2020). 
All companies and organizations whose focus is on various projects have touched on the importance of project management and project management information system use. Most of these organizations and companies are looking for practical, fast project management information systems with customizable dashboards for their portfolio to improve and increase productivity (Verzuh, 2015). It is essential that this project management information system be web-based and used for the project portfolio. Also, these systems should provide the ability to manage knowledge and data in various areas such as risk, time, related managers, etc. and have a good relationship with project control tools such as Project. The project management information system should also have appropriate facilities in the field of project communication (Charvat, 2003).

The collection of project information should be conducted with a degree of commitment to ensure that the project owners' information is kept confidential and a reasonable respect for privacy. Because of this commitment, protecting project stakeholders' privacy is an essential element in designing information systems (Ard, 2013). Individuals have the right, in certain circumstances, to refuse to disclose information about themselves or to restrict the use of information about themselves. People should be aware of this right (Ma, Harstvedt, Jaradat, \& Smith, 2020).

The primary purpose of collecting and using project information is to benefit the project stakeholders by improving the way the project works. Integration actually provides the acknowledgment that the original content of the information has not been altered or disturbed. As a result of this recognition, managers can trust the quality of information to make decisions in the project (Karim, 2011). A project must make reasonable efforts to ensure that information is accurate and up-to-date. Procedures should also be applied in place so that records are in order when not in use (Brown \& Holmes, 1986).

Project management information systems are defined as a pyramid structure with four levels of information resources. Levels of information depend on organizational structure. The highest level supports strategic planning and policy-making at the highest management level. Second levels of information resources assist in strategic planning and decision-making for management control (Zahedi \& Naghdi Khanachah, 2020). Second, information system users face several difficulties in setting up their respective enterprise systems and selecting related software products. An expert survey by Meyer shows that in only about $20 \%$ of cases surveyed do organizations have information systems that support multi-project planning and portfolio management (Zahedi \& Khanachah, 2020). In contrast, approximately $99 \%$ of organizations use information systems for scheduling and time management (Alavi, Kayworth, \& Leidner, 2005). The potential of existing PMIS is clearly not being exploited at all (Todorović, Petrović, Mihić, Obradović, \& Bushuyev, 2015).

The main purpose of this article is to provide a comprehensive and efficient model for project management in project-oriented organizations that all the main processes of project management, including planning, control, monitoring and coordination can be presented and cover all these cases. The present model covers both single project management and megaproject management.

This research consists of four main sections. In the second part of this article, it describes the conceptual and terminological foundations of this article. It provides an overview of the existing approaches for reference, valid and practical modeling on PMIS. A complete and detailed description of the research design and construction process resources and the architectural description of the proposed PMIS model are provided in Section Three. Finally, the final conclusion of this research is available in Section Four.

\section{Literature}

The Project Management Information System (PMIS) is a system consisting of tools and techniques for collecting, combining and integrating, and distributing the outputs of project management processes. The project management information system covers all parts of the project from the initial and final phases. Using this system, project changes can be controlled, reporting can be facilitated, and more accurate and better decisions can be made. According to a 2005 report by the Gartner Group, about $75 \%$ of projects that use Project Management Information Systems (PMIS) are successful, and about $75 \%$ of projects that use Management Information Systems are successful. The project does not benefit, they fail. This statistic shows the important role of information systems in project management (Zahedi \& 
Naghdi Khanachah, 2020), PMIS 'main function was to provide managers with "basic information about the cost-time performance parameters of a project and how these parameters interact." The nature and role of PMIS in the project management system, as shown in Figure 1, is essentially described as "a subset of achieving project goals and implementing project strategies" (Zahedi \& Khanachah, 2020).

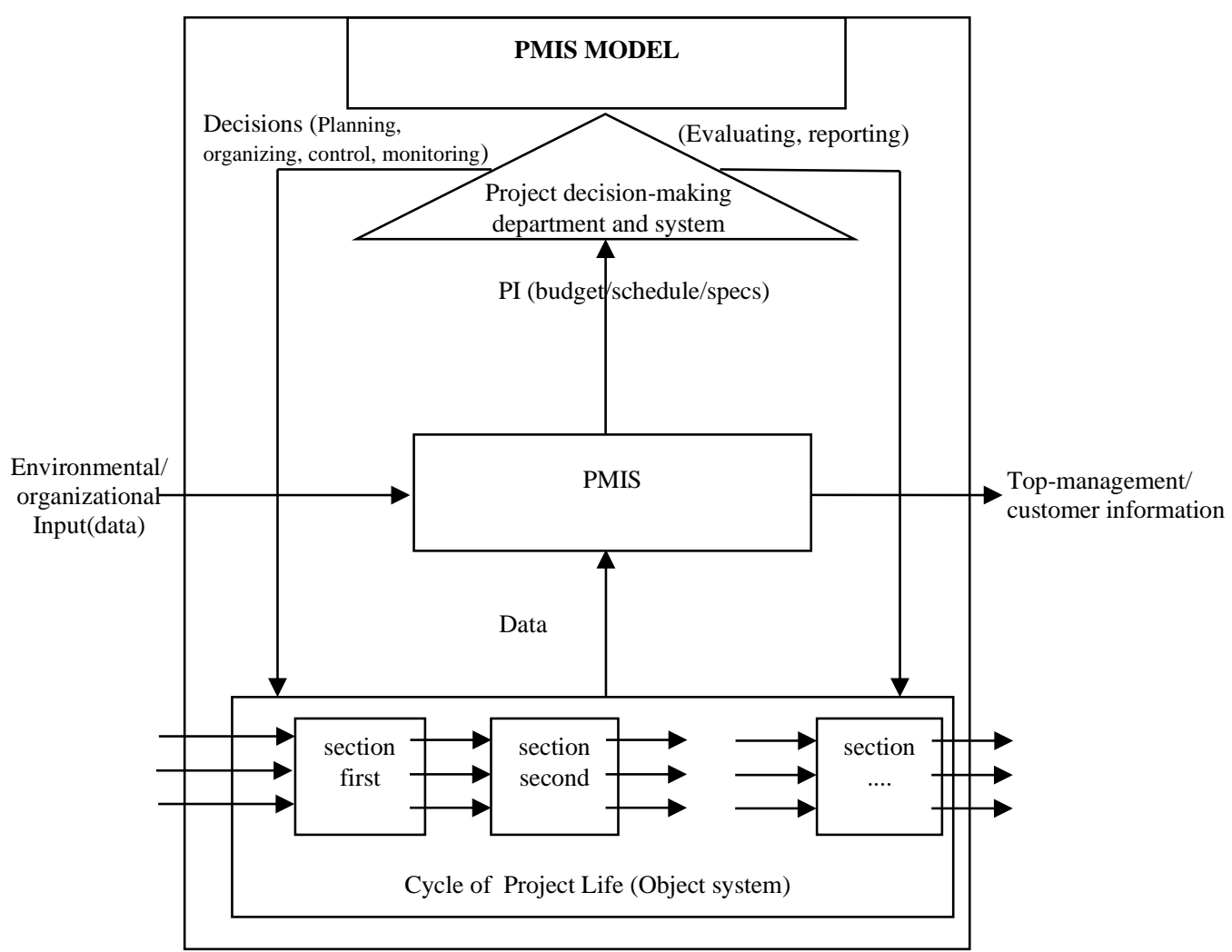

Figure 1. Function of PMIS within the project management system (Kostalova, Tetrevova, \& Svedik, $\underline{2015)}$

In addition to the critical role of PMIS in the field of successful project management, extensive and sufficient research has not been done to investigate the correct application in the operational phase and the effects that these types of systems have on project management results. Therefore, in this research, the importance of correct application of project management theories for development and growth in this regard has always been emphasized ( $\operatorname{Rad} \&$ Levin, 2002). It has also been found that the use of project management software has many drawbacks and limitations, both theoretically compared to the ideal PMIS by researchers (Zahedi \& Naghdi Khanachah, 2019). and in practice as perceived by project managers. An IS-based conceptualization and definition of project management software facilitates the import of knowledge from the IS field or discipline, knowledge that can provide a deeper understanding of the PMIS usage phenomenon and help in answering questions on the factors that explain the use and nonuse of PMIS, and on the actual impacts of these systems on project managers and project performance. This study will thus be founded on the recurrent constructs of antecedents and consequences of IS use developed in DeLong and McLean's (Hassan \& Mathiassen, 2018), IS success model (ISSM), later updated ("The DeLone and McLean Model of Information Systems Success: A Ten-Year Update", 2003), and in Davis et al.'s (1989) technology acceptance model (TAM). These models stand out by the continuance of their constructs after reviewing theories and models of IS using that focused on their chronological examination and their cross-influences and convergences. The ISSM incorporates information quality and system quality as antecedents of IS use, leading to individual IS impacts, that is, on users and their work (e.g., regarding their effectiveness) and organizational impacts (e.g., in regard to business strategy and performance). While the TAM explains IS use in a similar manner by the system's perceived usefulness and perceived ease of use. Both the ISSM and the TAM 
offer widely accepted and validated representations and explanations of the IS use phenomenon (Alalwan, Dwivedi, Rana, \& Williams, 2016; Burton-Jones \& Grange, 2013; Morosan, 2014; Rauniar, Rawski, Yang, \& Johnson, 2014; Raymond \& Bergeron, 2008).

\subsection{Functioning of applied models in the field of information and its role in the development of information systems}

Currently known information systems are practically systems that, due to their socio-economic nature, include software, hardware and peripheral organizational systems. The proposed models play a very important role in designing and implementing information systems and are appropriate. With the type of stage or level of design and implementation of information system, the most significant of these models include the following categories:

- What is usually focused on in conceptual models is problem solving and support processes, which help to document, analyze, and address the needs that an information system has developed to address them.

- Conversely, design models define an information system's overall structure by describing larger technical blocks called components. These types of components are not analyzed in detail.

- The main factor in successfully implementing the model is based on software programming and requires special technology.

Generally, information models describe static or dynamic aspects of information systems. As a result, models are distinguished as examples that provide information structures, e.g., data structures (data models), and those that provide information processes (process models) (Topi et al., 2010). In a nutshell: data models lead to the design of databases, whereas process models are generally used as a basis for the programming of functionality (Lino \& Valente, 2020). The design and implementation of information systems should be regarded as a construction process and is a topic of design science that explores how researchers can construct high-quality artifacts that are good solutions to practical problems (Badiru \& Osisanya, 2016).

\subsection{Reference models}

The content of this concept has grown significantly since the advent of strategic information systems planning. Strategic information systems planning was initially recognized as a factor in aligning information systems' goals with the organization's goals (Silva \& Hirschheim, 2007). In general, what can be said is the possibility of distinguishing between approaches that consider models as a direct representation of reality and approaches that follow the constructivist model. The second model considers the construction of one model or the construction of different instruments. This paper is based on the aforementioned constructivist understanding of the model. "According to this and according to Thomas, a reference model is defined as an information model that is used to support the construction of other models." The use of reference models is frequently based on the expectation that they can:

- Improve the "temporal aspect" by accelerating the development of information infrastructure.

- Improve the "cost aspect" by reducing overhead and additional costs.

- Facilitate communication, promotes innovative ideas, and improves "quality aspect" methods.

- Reduce project failure risks "risk aspect" (Francis, 2011).

Although it is widely accepted in the field of business informatics, the term reference model is often not used. Rather, the terms "standard model," "framework," or "architecture" are often used interchangeably. In the following, we will discuss all the different forms and scenarios as long as they conform to the characteristics of the definition provided above, are inherently conceptual, and at least include semi-formal information models (Salvi, Montalva Colomer, Arredondo, Prazak-Aram, \& Mayer, 2015).

\subsection{Agile and dynamic methods in the development of information systems models}

Recently, the application of agile methodology has become very popular, one of the reasons being the high flexibility in various projects. Agile methodology works much faster than traditional methodologies. One type of agile methodology is DSDM or Dynamic Systems Development Methodology. This method's focus is more on its acceptance by individuals and its degree of appropriateness in development projects. In this approach, each project is first checked to see if they 
meet the DSDM methodology criteria. Two important roles are critical in DSDM acceptance (Moniruzzaman \& Hossain, 2013).

One is the role of project manager and the other is the project manager. Project trainers and facilitators assist project managers in implementing this methodology. Instructors first review projects in terms of their features, project management methods, capability and risk assessment, and then recommend them to project instructors. This methodology pays a lot of attention to user participation in the development process. An incremental and repetitive approach or strategy is used in this method. The incremental or evolutionary approach means that before the whole system is implemented, a part of it is delivered to the user and then the feedback is integrated to be used again in the development process. From the combination of these two strategies, five strategies are formed, which are (Kerzner, 2017):

- Linear DSDM: where evolutionary strategy is used only once.

- One-pass DSDM: This strategy is created by combining one evolutionary approach and several iterative approaches.

- Hybrid DSDM: means a strategy that includes several evolutionary approaches. In some of these approaches, the iterative approach is used several times.

- Full DSDM: A combination of evolutionary and repetitive approaches, each several times.

- Phased DSDM: Use evolutionary approaches in several steps without using a repetitive approach In choosing any of these, one should pay attention to the type of project and the status of user participation. Before implementing these methodologies, it is best to reach an agreement between managers and trainers on project time and budget. The highlight of implementing these approaches is user satisfaction and participation in the development process. Getting feedback from the user and strengthening the user intervention in the project is basically an important action in the success of each incremental and repetitive approach (Kerzner, 2017).

\section{Proposed model}

The reference model construction discussed in this article was realized within a four-phase research process completed in a year and derived from a process model for reference model construction by Schutte. The reference model construction process is shown in Fig 1 (Kim, Kim, Tang, \& Kim, 2013). As we see in figure 2, this research has four main processes. It includes: "demonstrating problem", "presenting integrated PMIS model", " reliability", and "documentation". In the first part, we have demonstrated problem and the rest of research are elucidated here.

\subsection{The architecture of the integrated PMIS model}

The first step in designing the model is analyzing software system of project management. We have a comprehensive analyzing of applicable software and programs project control for the first sample. The next step is verifying review of literature and some standard of project management such as project management body of Knowledge (PMBOK).

The third step is Construction of the PMIS model, presenting an integrated model based on scientific knowledge of analyzing project control software and verifying the literature and experience of the author. In designing model, we have used structured methodology because traditional system design methods have had some inadequacy. It includes:

- relying on physical characteristic of system

- sharp tendency to bottom up approach in designing and execution

- doing consequently evolving cycle of system, the end of a step is beginning of the other step

- users do not have any critical impact on different phases of system 


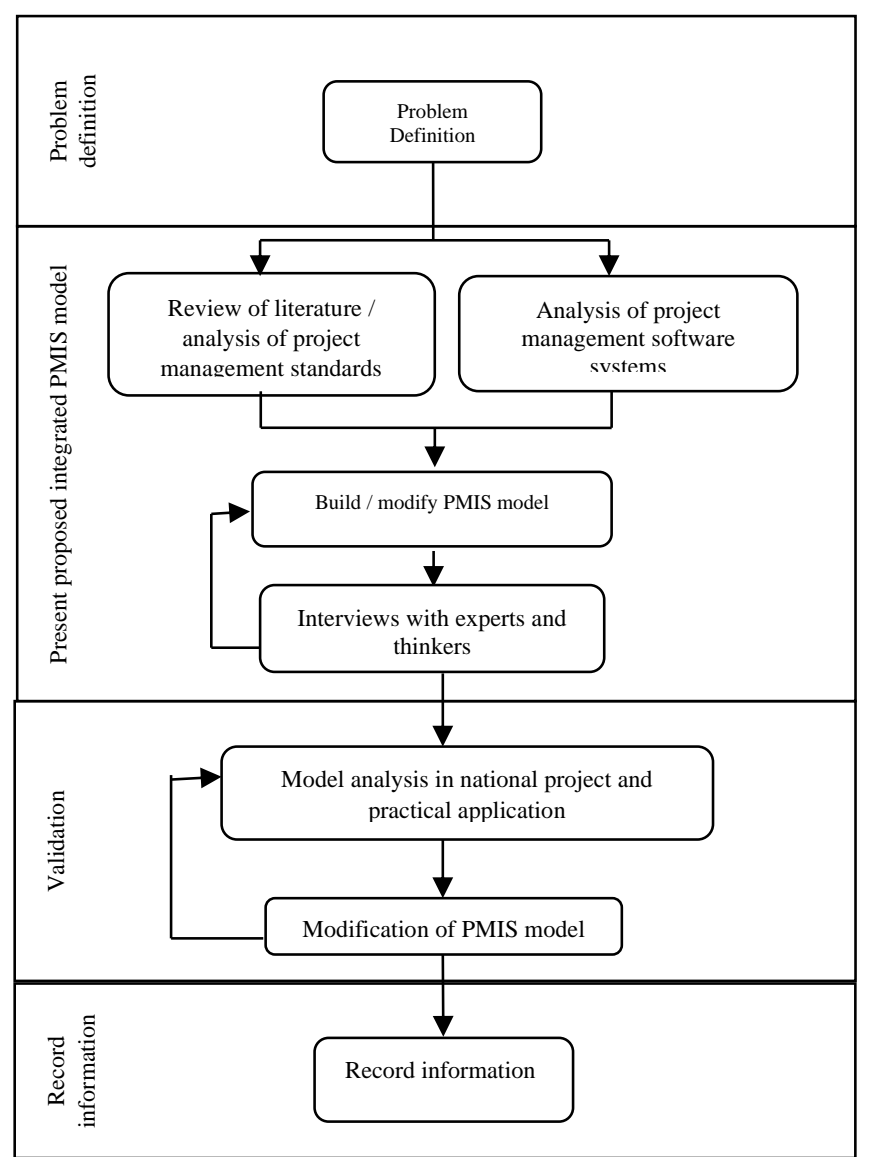

Figure 2. The PMIS model construction process (Kim et al., 2013)

In structured methodology, by different looking of traditional methodology and relying on the rational aspects of the system, we make its framework and then analyze, design, and execute the information system.

One characteristic of this method is using modular system. In this case system divided with top-down approach to smaller and independent sub system. Therefore, it is easy to examine and debugging. The important point in this research is communicating between project management elements by the help of structured methodology. We used of PMBOK standard. Developing the PMBOK model by this methodology is the same as the project management information system (PMIS).

The most important point in designing a connectional model is that this kind of design is based on analyzer study and experiences.

The more analyzers have system knowledge; their success percent would be more. This study's proposed model holds all responsibilities of the beginning, planning, executing, and end of project. We explain extensive control of organizational project process. The other characteristic of it is making into account employer information system, administer and inspector integrated. In present of the first model, we have used of project life-cycle too. Without considering the project's individual aims, all of them settle upon some phases in which make project life-cycle.

This life-cycle can be divided into the following phases (Karim, 2011):

- Initial: In the initial stage, the project ideas are produced, collected, recorded and reviewed and analyzed (idea generation phase). Their feasibility, profitability and strategic impact are analyzed to decide on their implementation (idea evaluation phase). This phase ends with the formal / no-exit decision taken by the management team (portfolio planning phase). 
- Planning: At this stage, the project plan and idea become an executable project plan and the necessary resources, including financial, human and other resources (which is related to project preparation) are provided. The project manager also modifies the project plan (detailed planning).

- Execution: At this stage, the project idea is realized through the project's resources (project execution). Project implementation information is collected and analyzed for control purposes (Project Controlling). The useful, final information is then collected with the approval of project knowledge experts to obtain an overview of the project status (portfolio control).

- Termination: At this stage, the project results are sent to the senior official and project manager (internal project termination). In addition, the company completes the project and tries to learn from experiences (especially the completion of a foreign project).

\subsection{Information collection}

Identifying and collecting the information requirement of project managers for designing the PMIS model is very important. It is evident that project management use for decision-making must be reliable. In identifying and recognizing the requirement of statistical community, we have used managers and administers of some national project. Most of the community members are not familiar with the project management of information systems and have used conversation methods. Verified projects of this research are in table 1 .

Table 1. Some projects reviewed during the investigation

\begin{tabular}{|c|c|c|}
\hline No. & Project name & Employer \\
\hline 1 & $\begin{array}{c}\text { Implementation of national water channels from CHALOOS to } \\
\text { SARDABROOD }\end{array}$ & Mazandaran Regional Water Company \\
\hline 2 & $\begin{array}{c}\text { Water supply from the "SOLEYMAN TANGE" dam to the city of } \\
\text { SARI }\end{array}$ & Mazandaran Regional Water Company \\
\hline 3 & Water supply from the "ALBORZ" dam to the city of Babol & Mazandaran Regional Water Company \\
\hline 4 & $\begin{array}{c}\text { Maintenance of MAZANDARAN electricity distribution networks } \\
\text { parks corporation }\end{array}$ & $\begin{array}{c}\text { Mazandaran Regional Electric Company } \\
\text { parks corporation }\end{array}$ \\
\hline 6 & $\begin{array}{c}\text { Conduct operations of surface water and asphalt of KIYASAR } \\
\text { industrial park }\end{array}$ & $\begin{array}{c}\text { Mazandaran small industries and industrial } \\
\text { parks corporation }\end{array}$ \\
\hline 7 & MAZANDARAM food industries cluster & $\begin{array}{c}\text { Mazandaran small industries and industrial } \\
\text { parks corporation }\end{array}$ \\
\hline
\end{tabular}

\subsection{Introducing system}

Project management information system aims to collect correct data in correct place, by feasible device and in correct time and location economically. The results of process are for developing and make financial obligations. It is a communicating device for standard describing requirements and elements of project team. They use for assessing, inspecting, guidance and planning of project to get its aims. Some of the most important goals of system are planning and control of expenditure, time planning, reporting, predicting and control of all elements of project. Project management need to an information system for documentation. Documentation includes: strategies, policy, prescription, forms and checklist or combination of it. It is an integrated system for user in which supply information about supporting process, management and decision making functions for planning and project goals control.

As we said before, the proposed model was gathered by research literature and the researcher's recognition of verified information. We have used of expert views on project management, preliminary reports, financial, technology for gathering necessary information. In this case projects management information system has included so many areas. It is a communicating device for standard describing 
requirements and elements of project team. They use for assessing, inspecting, guidance and planning of project to get its aims. Some of the most important goals of system are: planning and control of expenditure, time planning, reporting, predicting and control of all elements of project. Project management need to an information system for documentation. Documentation includes: strategies, policy, prescription, forms and checklist or combination of it. It is an integrated system for user in which supply information about supporting process, management and decision-making functions for planning and project goals control.

\subsection{Proposed model in hierarchical structure}

Data flow diagrams are hierarchically used for modeling systems in terms of processing; therefore dataflow diagrams have different levels. As shown in figure 3, we have designed our zero-level conceptual model for the project management information system using a structured methodology. At this level only basic information is shown and details are not addressed. At first, we define project and then recognize and predict work volume and then receive necessary credit in project management. By recognizing project activities and defining work breakdown structure, time planning of project is made. After estimating necessary budget, preparation process begins to buy service and equipments. And then consultant, administrator and employer teams would be selected.

Project management is very important. It is clear that designed information systems based on requirements can strengthen managers' decision-making ability (Silvius, Kampinga, Paniagua, \& Mooi, 2017). In identifying and recognizing the requirement of statistical community, we have used managers and administers of some national project because most of the community are not familiar with the project management of information systems we have used in conversation methods (Kerzner, 2017). Verified projects of this research are in table 1.

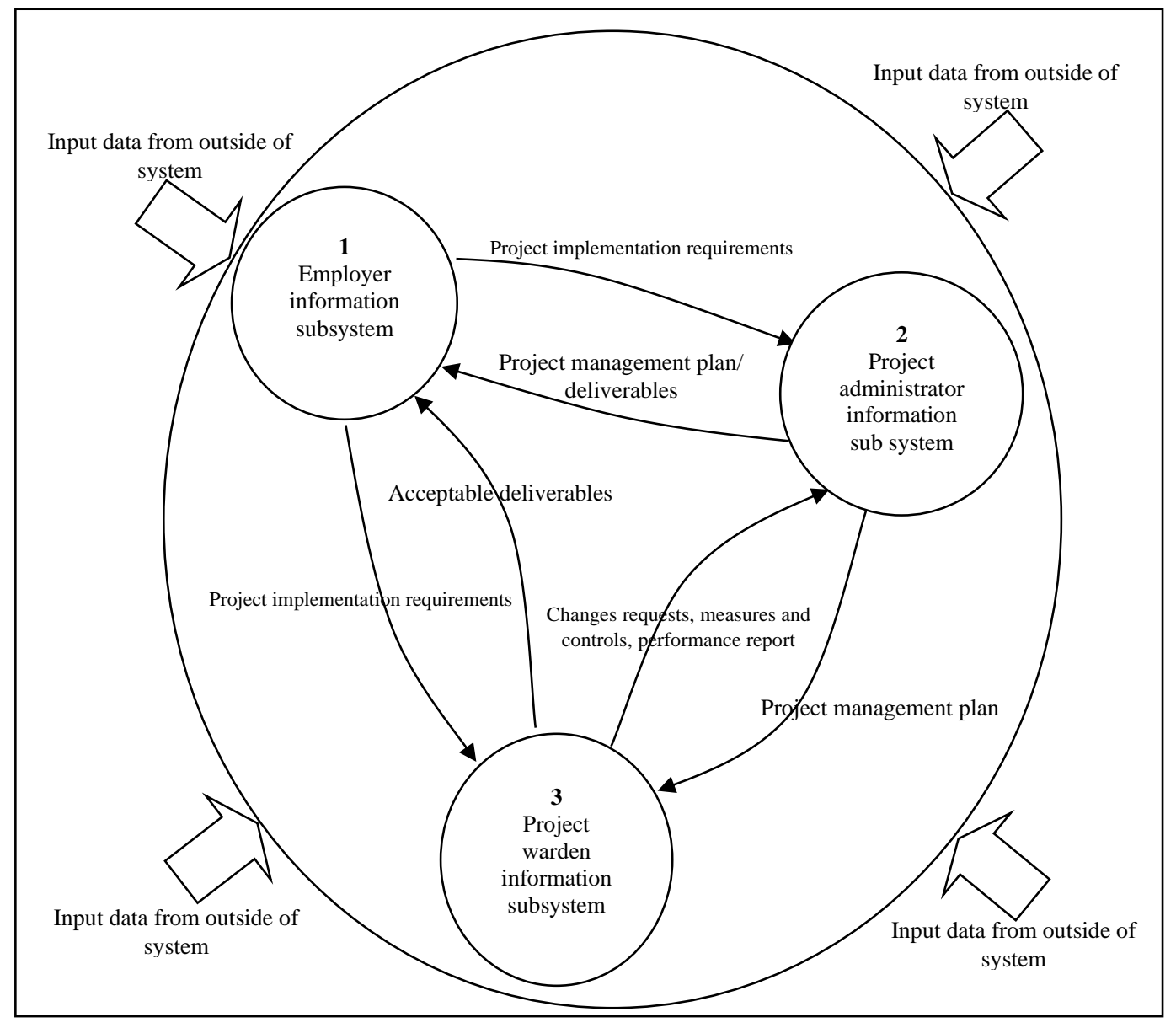

Figure 3. Conceptual level in proposed model 
As we explained before, proposed model have three main subsystems. We could name them as project administrator subsystem, employer subsystem and inspector subsystem. They are formed of four sections and they have subsections too. Figure 4 and 5 show employer and administer subsystem of a model. For proposed model, we have included three main subsystems in which each of them have four sections. Each section has some subsections too. It has been shown in figure 6 .

Management should control expenditure to do so. We should use quality control for making sure of project feasibility. We could do so by assessing buying/service sides, controlling inspectors, suppliers and sellers in project and different aspects of technology, financial and preparation would end. At last for gathering, categorizing, storing, and distributing project information, each member of the project, including employer groups and or non-employer, can send or receive necessary information at any time and any location needed.

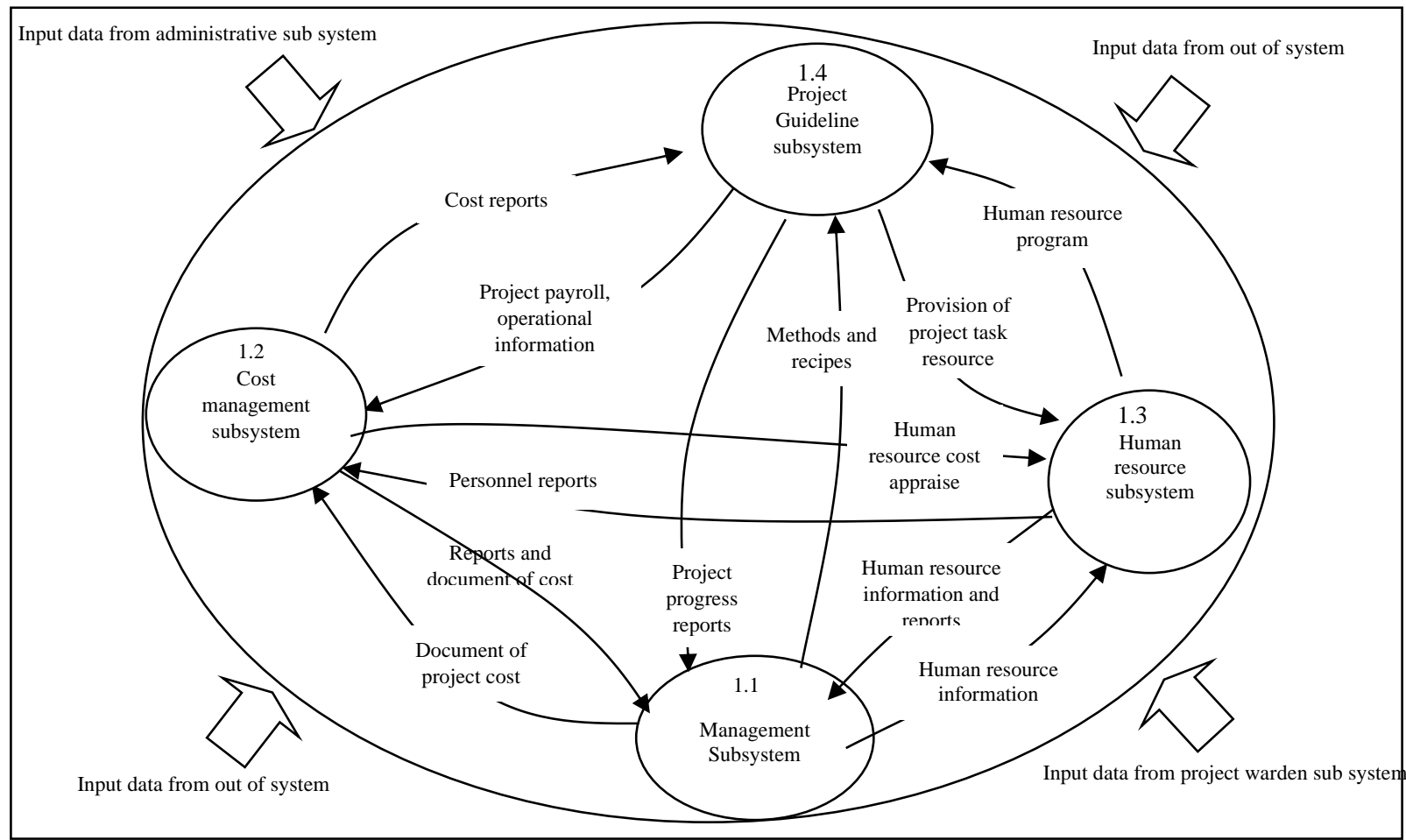

Figure 4. Employer subsystem in first level of proposed model 


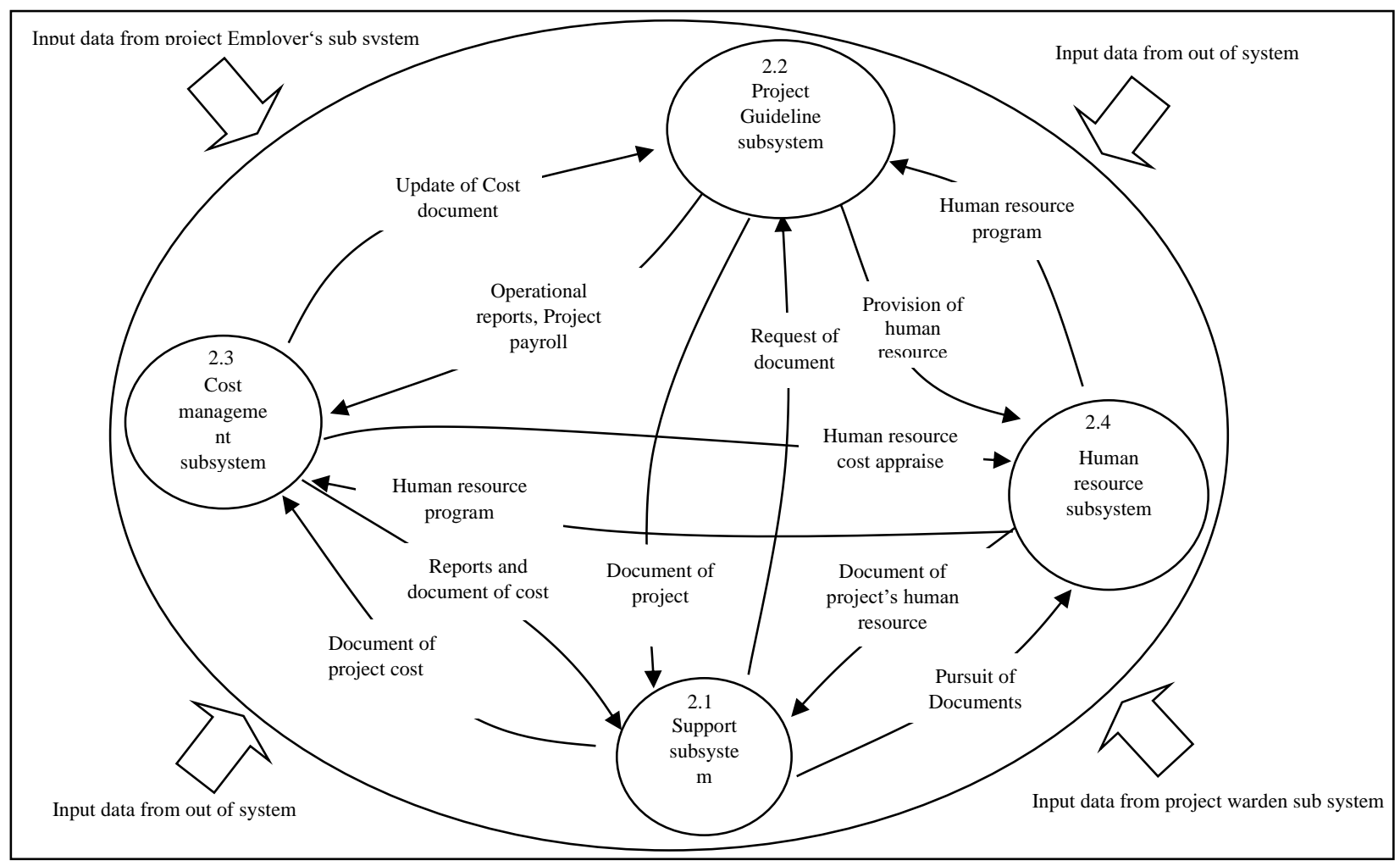

Figure 5. Administrative subsystem in first level of proposed model 


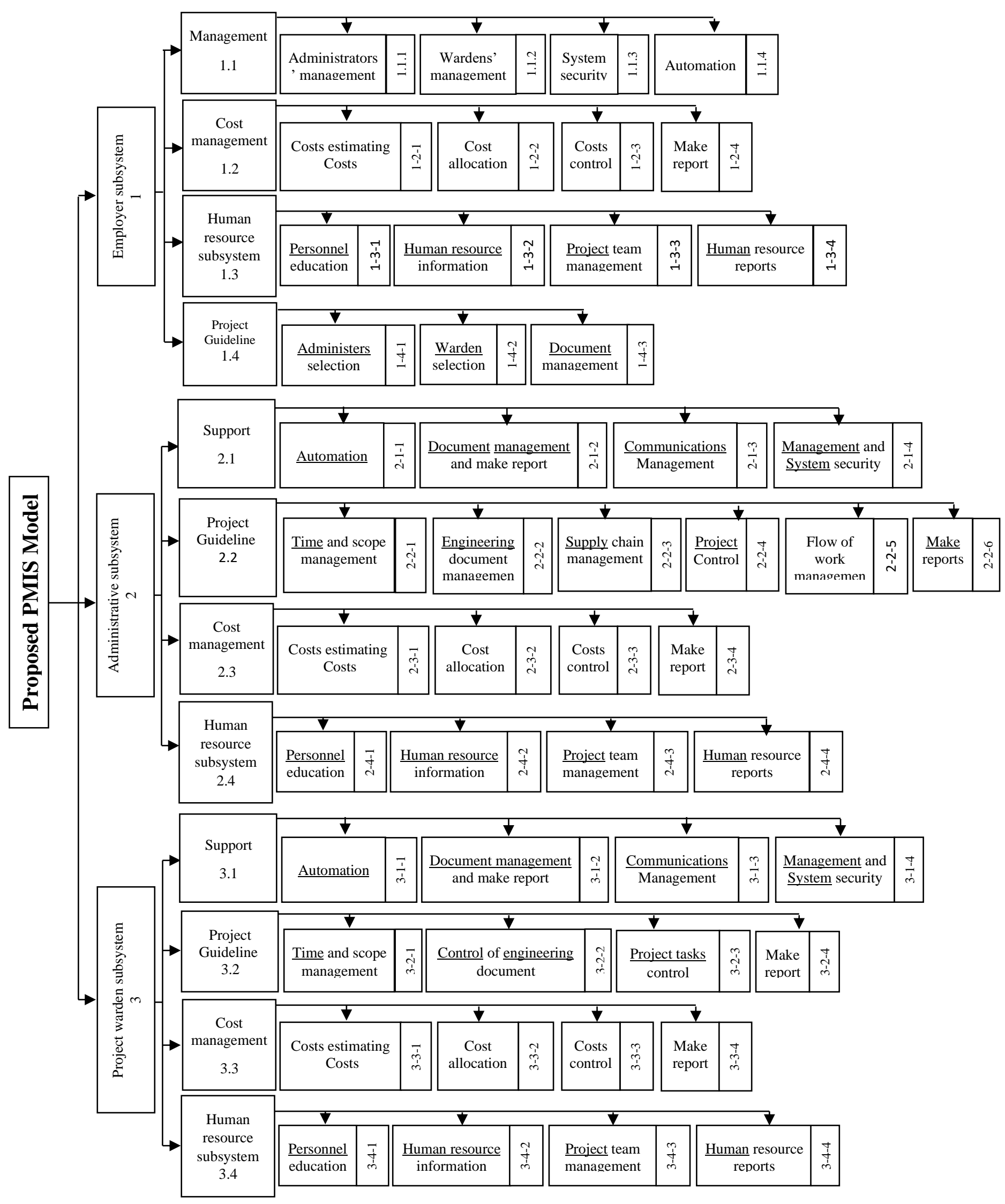

Figure 6. Section and sub section in proposed model of PMIS 


\subsection{Requirements}

1. During the research process, the following general requirements were inferred for modeling project key data, project structures, baselines, and scenarios:

2. Relation of financial, human resource, guiding section of three main member of project. (Employer, administer and inspector)

3. Projects, working pad, and activities need a comprehensive collection of characters to define, explain, and control it fully.

4. Work breakdown structure has so many levels.

5. All project management methods would apply to each level of analyzing structure, project and its programs.

6. System should store some base line of project for management goals and its control.

7. A general requirement of all section of project management information system is files management and its documentations.

8. Relation to interested party is important in all projects. We could control it by letters, meetings, and calling, besides; we need an integrated databank of information and interested parties' records to be used on other parts of the plan.

9. Because of engineering work volume in engineering project, using special tools of management is a generality. This subsystem in the integrated information system of management project and its cooperation with other parts of the project are prominent advantages.

10. Supply chain management has three parts: buy and preparatory of project- logistic management- site stock control. Because of developing and importance of finance and technology section, preparatory section would be more important.

11. We need to collection of tools for certainty of assessing and quality control.

12. We always have so many process in which by all subsystem is only for the same organization. If they be out of organization, simultaneously should use of artificial and islanded system beside main system. Therefore we require to a sample in an integrated environment to be used with all other subsystem.

13. If we have various reports, there are so many unpredictable reports too. In different parts of the program, we should have models that have compatibility with all other reports and apply them.

14. Executing project by reasonable cost and according to approved budget.

15. Suitable human resource management in project.

In this research, we introduce an integrated model that tries to meet the needs mentioned above by introducing a very basic data structure called "initiative"(Fig. 4). This model has three main subsystems in which financial and human resource departments are interrelated (requirement 1).

In second subsystem, we could do planning and control project's activities in regard to project life cycle. We explain work breakdown structure by various manufacturing levels and baseline too (requirement 2, 3 and 5). Proposed model would be applicable to all projects by the aid of general data structure for different goals, project management methods, like quality, resource and cost management in which they categorize and then execute it (requirement 4). File management and documentation is a general requirement. We do these sections in three subsystems: 1-4-3, 2-1-2, 3-1-2 (requirement 6).

Communication management does all processes of three main subsystems (requirement 7). Engineering document management subsystem on project management's integrated information system is an outstanding advantage (requirement 8 ). In the proposed sample, we have supply chain management with three parts: buy and supply, logistic management, site stock control. Buy and supply is very important because of financial and technological sensitivity (requirement 9). In the proposed model, we present the inspect and control section to help users implement quality control in the project (requirement 10). In the work cycling management section, the disparate organization process has been modeled and is useable in an integrated environment (requirement 11). In this model and in all section, we have various reports (requirement 12); also we have some parts for cost control and human resource management (requirement 13, 14). 


\subsection{Validation}

This step's purpose was to validate, modify and stabilize the initial construction of the integrated model. This phase has three parts, which are described below:

a) Interviews with experts in the field. A series of interviews with project management and project information systems specialists have been conducted to gather more empirical evidence for the reference model for validation purposes. This formative assessment using guided interviews consisted of basically two parts. In the first part, the knowledge and experience of domain specialists were determined. In the second part, the experts were confronted with the reference model and asked to provide detailed feedback on the model's strengths and weaknesses. After that, possible improvements were discussed. If necessary, the results of the interview, the reference model is refined or redesigned. It was then concluded that domain experts agreed on the reference model propositions. The selection of domain specialists follows both chain sampling and theoretical sampling (Gasson \& Waters, 2013).

b) Practical application. Validation of the reference model was obtained through interviews with experts in the field and the case of applied projects.

c) Modification of the reference model. The experience gained in the above projects was also used to modify the reference model.

\section{Conclusions}

Increasing use of computers and using tools with a deficient resource made PMIS a necessity. This paper has introduced an integrated model of PMIS, presented A comprehensive and new model for project and project portfolio management. By providing more practical aspects of project management and providing data structures and processes that have been theoretically and empirically proven, our model tries to overcome deficiencies of existing reference models. The first version of this model's development was a four-step research process that achieve in one year. Our aim in this research was introducing a new model for integrating information system of project management. By introducing the new model which including project warden, administrative and employer subsystems, we could cope with deficit of project and cover more aspects of project management. Using this model also prepares a reliable data structure and financial process for its users.

All three of these subsystems must be interrelated. The client information system must provide project implementation requirements to the project executor information system and receive the project management plan and deliverables from it. This subsystem should also give project implementation requirements to the project warden information system and get acceptable deliverables. Project administrator information system and project warden information system also swap some information that each other; such a way that former give project management plan information to latter and get changes requests, measures, controls, and performance report information.

\section{References}

Alalwan, A. A., Dwivedi, Y. K., Rana, N. P., \& Williams, M. D. (2016). Consumer adoption of mobile banking in Jordan: Examining the role of usefulness, ease of use, perceived risk and selfefficacy. Journal of Enterprise Information Management.

Alavi, M., Kayworth, T. R., \& Leidner, D. E. (2005). An empirical examination of the influence of organizational culture on knowledge management practices. Journal of management information systems, 22(3), 191-224.

Ard, B. (2013). Confidentiality and the problem of third parties: Protecting reader privacy in the age of intermediaries. Yale JL \& Tech., 16, 1.

Badiru, A. B., \& Osisanya, S. O. (2016). Project management for the oil and gas industry: a world system approach. CRC Press.

Brown, R., \& Holmes, H. (1986). The use of a factor-analytic procedure for assessing the validity of an employee safety climate model. Accident Analysis \& Prevention, 18(6), 455-470.

Burton-Jones, A., \& Grange, C. (2013). From use to effective use: a representation theory perspective. Information Systems Research, 24(3), 632-658 .

Charvat, J. (2003). Project management methodologies: selecting, implementing, and supporting methodologies and processes for projects. 
Choo, C. W. (2002). Information management for the intelligent organization: the art of scanning the environment. Information Today, Inc.

Davis, F. D., Bagozzi, R. P., \& Warshaw, P. R. (1989). User acceptance of computer technology: A comparison of two theoretical models Management Science, 35, 982-1003

DeLone, W. H., \& McLean, E. R. (2003). The DeLone and McLean model of information system success: a ten-year update. Journal of Management Information Systems, 19(4), 9-30.

Francis, M. (2011). A model for assessing the anticipated relative financial impact of implementing the tools of lean manufacturing on a manufacturing cencern.

Gartner Group (2005). Delivering IT's Contribution: The 2005 CIO Agenda. Gartner EXP Premier Reports. Gartner, Inc. Stamford.

Gasson, S., \& Waters, J. (2013). Using a grounded theory approach to study online collaboration behaviors. European Journal of Information Systems, 22(1), 95-118.

Genc, E., Dayan, M., \& Genc, O. F. (2019). The impact of SME internationalization on innovation: the mediating role of market and entrepreneurial orientation. Industrial Marketing Management, 82, 253-264.

Hassan, N. R., \& Mathiassen, L. (2018). Distilling a body of knowledge for information systems development. Information Systems Journal, 28(1), 175-226.

Karim, A. J. (2011). Project management information systems (PMIS) factors: an empirical study of their impact on project management decision making (PMDM) performance. Research Journal of Economics, Business and ICT, 2.

Kerzner, H. (2017). Project management: a systems approach to planning, scheduling, and controlling. John Wiley \& Sons.

Kim, S., Kim, S., Tang, L. C. M., \& Kim, G.-H. (2013). Efficient management of construction process using RFID+ PMIS system: a case study. Applied Mathematics \& Information Sciences, 7(1), 19-26.

Kostalova, J., Tetrevova, L., \& Svedik, J. (2015). Support of project management methods by project management information system. Procedia-Social and Behavioral Sciences, 210, 96-104.

Lino, J. C., \& Valente, I. (2020). A Conceptual Framework for effective BIM-enabled Information Management in Railways.

Ma, J., Harstvedt, J. D., Jaradat, R., \& Smith, B. (2020). Sustainability driven multi-criteria project portfolio selection under uncertain decision-making environment. Computers \& Industrial Engineering, 140, 106236.

Moniruzzaman, A., \& Hossain, D. S. A. (2013). Comparative Study on Agile software development methodologies. arXiv preprint arXiv:1307.3356.

Morosan, C. (2014). Toward an integrated model of adoption of mobile phones for purchasing ancillary services in air travel. International Journal of Contemporary Hospitality Management.

Rad, P. F., \& Levin, G. (2002). The advanced project management office: a comprehensive look at function and implementation. CRC press.

Rauniar, R., Rawski, G., Yang, J., \& Johnson, B. (2014). Technology acceptance model (TAM) and social media usage: an empirical study on Facebook. Journal of Enterprise Information Management.

Raymond, L., \& Bergeron, F. (2008). Project management information systems: an empirical study of their impact on project managers and project success. International Journal of Project Management, 26(2), 213-220.

Salvi, D., Montalva Colomer, J. B., Arredondo, M. T., Prazak-Aram, B., \& Mayer, C. (2015). A framework for evaluating Ambient Assisted Living technologies and the experience of the universAAL project. Journal of Ambient Intelligence and Smart Environments, 7(3), 329-352.

Serrador, P., \& Pinto, J. K. (2015). Does Agile work?-A quantitative analysis of agile project success. International Journal of Project Management, 33(5), 1040-1051.

Silva, L., \& Hirschheim, R. (2007). Fighting against windmills: strategic information systems and organizational deep structures. MIS Quarterly, 327-354.

Silvius, A. G., Kampinga, M., Paniagua, S., \& Mooi, H. (2017). Considering sustainability in project management decision making: an investigation using Q-methodology. International Journal of Project Management, 35(6), 1133-1150. 
Todorović, M. L., Petrović, D. Č., Mihić, M. M., Obradović, V. L., \& Bushuyev, S. D. (2015). Project success analysis framework: A knowledge-based approach in project management. International Journal of Project Management, 33(4), 772-783.

Topi, H., Kaiser, K. M., Sipior, J. C., Valacich, J. S., Nunamaker Jr, J. F., de Vreede, G., \& Wright, R. (2010). Curriculum guidelines for undergraduate degree programs in information systems: ACM.

Verzuh, E. (2015). The fast forward MBA in project management: John Wiley \& Sons.

Zahedi, M. R., \& Khanachah, S. N. (2020). The effect of knowledge management processes on organizational innovation through intellectual capital development in Iranian industrial organizations. Journal of Science and Technology Policy Management.

Zahedi, M. R., \& Naghdi Khanachah, S. (2019). Measuring the Impact of Organizational Social Capital on Organizational Innovation(Case Study: Iran Khodro Industrial Group).

Zahedi, M. R., \& Naghdi Khanachah, S. (2020). Designing and implementing a model of organizational readiness assessment to become a knowledge-based organization(Case study an Iranian research center). 